\title{
Comparison of Three Types of Stud Attachments on Retention and Strain Energy in the Mandibular Implant Supported Overdentures
}

\section{Gholamreza Esfahanizadeh ${ }^{1}$, Parvaneh Lavasani Navai ${ }^{2}$}

${ }^{1}$ Assistant Professor, Department of Prosthetic, School of Dentistry, Islamic Azad University, Tehran, Iran.

${ }^{2}$ General Dentist, Tehran, Iran.

*Corresponding Author: Gholamreza Esfahanizadeh, Assistant Professor, Department of Prosthetic, School of Dentistry, Islamic Azad University, Tehran, Iran.

\section{Abstract}

Background: The present in vitro study assessed the effects of three different Stud attachments on the retention and strain energy in the mandibular implant-supported overdentures.

Methods: Two parallel implants (Implantium System) were placed on the mandibular canines regions and a chrome-cobalt casting framework was prepared as the denture base. The implant fixtures were installed on the canine location and the pulling was performed by three orthodontic wires in the Instron machine with a speed of $0.5 \mathrm{~min} / \mathrm{mm}$. Dislodging forces were applied to the housings in two vertical and oblique directions on three different Stud attachments (Ball, Kerator, Positioner). All three wires were connected to the device in the vertical position while one wire was separated from the molars region in the oblique loadings. The retention of these three attachments was statistically analyzed by means of one-way analysis of variance.

Results: Significant differences were found between the attachments $(F(2,15)=33.01, p<0.0001)$. Furthermore, Retention forces in the oblique loadings were significant differences between the attachments $(F(2,15)=175.10$, $p<0.0001)$. The effect size, calculated using eta squared, was 0.95, which is considered large. The strain energy was 4.08, 3.05 and 1.04 J for the Ball, Positioner and Kerator attachments in the vertical loadings and 4.05, 1.44 and $3.07 \mathrm{~J}$ in the oblique loading respectively.

Conclusion: The retentive forces and strain energy of ball attachments were greatest than other studied attachments in the vertical and oblique loadings.

Keywords: Stud attachments, Retention force, Strain energy, Overdenture

\section{INTRODUCTION}

Nowadays, implant-supported overdentures are playing an importantrole in prosthesis treatments and they are becoming the treatment of choice for the completely edentulous patients as they can improve the quality of life of these patients [1]. Since retentions of mandibular denture are less than those of maxillary ones [2], implant-supported mandibular overdentures are more of a concern. Thus, retentions of overdentures will be increased by placement of two to four implants in the mandibular anterior areas and employing attachments on the implants [3].

The use of implant enhances the stability and retention of overdenture [4]. Furthermore, implants can improve the ability to chew, increase chewing cycles, and improve the quality of life associated with oral health [5]. Some of the advantages of this method over the other implant-supported treatments include: using minimum implant numbers (two implants), lower cost for both patient and dentist, and simpler surgical as well as prosthesis replacement techniques $[6,7]$. Furthermore, many various attachments have been designed and used, with their own advantages and disadvantages, in this regard, endooseous implants have been applied and reported by attachments for retention of overdentures, which are reliable studs for overdentures [8]. 
Comparison of Three Types of Stud Attachments on Retention and Strain Energy in the Mandibular Implant Supported Overdentures

The concept of attachment retention originates from implant-supported overdentures in Switzerland in 1989 and was published by Gilmore about 60 years ago $[9,10]$. An ideal attachment should reduce denture movements without imposing extra stress on implants [11]. Various attachment systems have been used for implant-supported overdentures. Attachment can be made from precious or non-precious alloys, which affects their mechanical properties and resistance to wear [12]. There are different types of attachments by retention mechanisms including magnets, stud attachment, and bar \& clip. The stud and magnet types are more widely used because of their easier application [13, 14]. Magnets are no longer used because of gradual decrement of their magnetic properties and corrosion in the wet environment of the mouth [15-17].

Despite providing more retention, bar and clips are less used because of having more clinical and laboratory procedures [18]. The simplest and most commonly used attachments are studs [19]. Several studies have shown that a patient's short-term satisfaction with bar and ball attachments is similar, and this magnitude is greater than magnets [2022]. Although some researchers argue that there is insufficient evidence to confirm that the use of bar or ball attachments in implant-supported overdentures in completely edentulous patients is able to improve prosthesis retention and patient satisfaction [23].

In recent years, different types of bar attachments are more widely used due to their easier application in limited prosthetic spaces, lower cost, easier cleaning and less technical complexity compared to ball attachments [18, 24, 25]. Although ball attachments may initially be less expensive for the patients than the bar attachment type, its components need to be activated [26], and permanent withdrawal will reduce its retention [27-30].

Factors affecting the selection of attachments include available space, required maintenance period, replacement of prosthetic components, force distribution on the surrounding bones and retention [31]. One of the main concerns among both patients and clinicians is the retention of overdenture. It has been observed that there is a direct relationship between the lack of movement of overdenture and patients' satisfaction [9, 32]. Reduction of retention or vertical dimension of occlusion (VDO) adjust are common complications [33]. Retention force is affected by a number of implants and their position, type of attachment and the material used [3].
In addition, applied forces on overdentures are affected by different factors such as force type; elastic strain energy; material, design, and size of attachments; shapes of basic teeth; and material and location of implants. Absorbed strain energy causes gradual deformation of attachment components which in turn reduces the amount of prosthesis retention after a defined number of cycles of prosthesis placement [34].

In this regard, one of the current concerns of prostho dontists is the selection of suitable attachments for overdentures, as attachments apply stress on the teeth and in turn on the bones.

Selecting a proper attachment can offer the patients a variety of advantages [35] and it has been found that clinicians select different types of attachments based on their experiences and interests [36].

On the other hand, it seems that the absorbed strain energy by attachment components during full separation from the abutment, affect the shape of attachment as a probable anticipation factor, which this guides physicians in the selection of suitable attachments and increment of overdentures [11].

The aim of the present study was to assess the effects of three types of attachments (Ball, Kerator, and Positioner) on retention and strain energy of implantsupported mandibular overdentures.

\section{MATERIALS AND METHODS}

This in-vitro research studied three types of attachments (Ball, Kerator, positioner) on maxillary canine implants. For simulation, an investment acrylic resin and two parallel implant systems (implantium, UK Ltd, Shrewsbury, UK) were placed on the canine area. All the tests were performed on this model and chromecobalt casting framework was built as denture base of the edentulous area. This framework was remained attached to the overdenture base during the test.

The overdenture test was an acrylic resin (Caulk, Milford, DE) with removable components that occupied where the chrome-cobalt casting framework surrounded two implants [10].

All attachments systems were activated by screwing abutment lock components to the implant and placing its complementary components on the surface. The implant components also were placed by relining VLC (DENTSPLY, York, PA). Many references holes on the site were used to fix the overdenture in the framework, which their alignment with ridges of the framework in each attachment was checked[9]. 
Comparison of Three Types of Stud Attachments on Retention and Strain Energy in the Mandibular Implant Supported Overdentures

These 3 attachment systems were examined by Instron materials 5500 testing machine (Instron, Canton, MA). The velocity of $0.5 \mathrm{~mm} / \mathrm{min}$ was used to vertical separation of samples. This speed si as the nearest speed to the denture movement on the ridge during chewing [37].

This model is considered to the device by 3 orthodontic cords, which tension is transferred to the framework through these cords to the 3 loops. The wires were connected to 3 loops in the middle of canine, right and left molars. The total framework acted as a retromolar pad that in turn, acted as a positive seat.

A vertical three-point tension by Instron Machine was applied to attachment housing in order to determine vertical retention forces and rebuilt oblique force. The right molar area cord was separated. The absorbed strain energy during removal of attachment in each direction was recorded by Material Testing Series IX [9].

Abutment s of samples were tested while screwing to the Implantium System implants. Ridges, washers,

and screw inside the framework protected each attachment. Moreover, both measures (retention and tension forces) were analyzed separately.

Retention and stress energy for those three groups were statistically examined by One-Way variance analysis and Turkey multiple comparison.

\section{Statistical ANAlysis}

Data analysis was carried out using IBM SPSS Statistics for Windows, Version 22.0 (IBM Crop., Armonk, NY, USA). The Kolmogorov-Smirnov test was used to evaluate the normality of the data. A oneway ANOVA, followed by the Duncan post-hoc test, was used to compare between the attachments (Ball, Positioner and Kerator). Furthermore, Eta squared, which estimated the magnitude of the attachment differences was calculated. All statistical tests were 2-tailed and a p-value less than 0.05 was considered statistically significant.

\section{RESULTS}

Table1. The Retention forces of 3 attachments in vertical and oblique loadings

\begin{tabular}{|c|c|c|c|c|c|c|c|}
\hline \multirow{2}{*}{$\begin{array}{l}\text { Retention } \\
\text { forces }\end{array}$} & \multicolumn{3}{|c|}{ Attachments } & \multirow[t]{2}{*}{$F(2,15)$} & \multirow[t]{2}{*}{ P-Value } & \multirow{2}{*}{$\begin{array}{l}\text { Effect Size } \\
\text { (Eta } \\
\text { Squared) }\end{array}$} & \multirow{2}{*}{$\begin{array}{l}\text { Pairwise } \\
\text { significance } \\
\text { differences }\end{array}$} \\
\hline & Ball & Positioner & Kerator & & & & \\
\hline $\begin{array}{l}\text { Vertical } \\
\text { loadings }\end{array}$ & $\begin{array}{l}67.78 \\
(6.50) \mathrm{a}\end{array}$ & $47.25(3.05)$ & $\begin{array}{l}45.87 \\
(5.51)\end{array}$ & 33.01 & $<0.0001$ & 0.81 & $\begin{array}{l}\text { Ball, } \\
\text { Positioner>Kerator }\end{array}$ \\
\hline $\begin{array}{l}\text { Oblique } \\
\text { loadings }\end{array}$ & $\begin{array}{l}88.07 \\
(5.11)\end{array}$ & 39.19 (2.09) & $\begin{array}{l}81.68 \\
(6.48)\end{array}$ & 175.10 & $<0.0001$ & 0.95 & \begin{tabular}{|l|} 
Ball, \\
Kerator>Positioner
\end{tabular} \\
\hline
\end{tabular}

$\mathrm{a}=$ Values are given as mean (standard deviation)

\begin{tabular}{|c|l|l|l|l|}
\hline Effect Size & Use & Small & Medium & Large \\
\hline Correlation & & 0.1 & 0.3 & 0.5 \\
\hline$\eta^{2}$ & Anova & 0.01 & 0.06 & 0.14 \\
\hline
\end{tabular}

$0.01<=$ eta $\mathrm{sq}<0.06$ : small effect, $0.06<=$ part eta $\mathrm{sq}<0.14$ : medium effect, part eta sq $>=0.14$ : large effect

As presented in table 1, a one-way ANOVA was used to evaluate the differences of the retention forces in the vertical loadings. Significant differences were found between the attachments $(F(2,15)=33.01$, $\mathrm{p}<0.0001$ ), with a large size effect (eta squared $=0.81$ ). Furthermore, retention forces in the oblique loadings showed significant differences between the attachments $(\mathrm{F}(2,15)=175.10, \mathrm{p}<0.0001$, eta squared $=0.95$ ). The effect size, calculated using eta squared, was 0.95 , which is considered large.

The strain energies were 4.08, 3.05 and $1.04 \mathrm{~J}$ for the Ball, Positioner and Kerator attachments in the vertical loadings and 4.05, 1.44 and $3.07 \mathrm{~J}$ in the oblique loading respectively.

Post hoc comparisons using the Duncan test indicated that the mean score for the Kerator group ( $M=45.87$, $\mathrm{SD}=5.51$ ) obtained significantly lower scores than Ball (67.78, SD=6.50) and Positioner $(M=47.25, S D=3.05)$ groups.

Retention forces in the oblique loadings score were significantly lower for Positioner $(M=39.19, S D=2.09)$ than for Ball $(M=88.07, S D=5.11)$ and the Kerator $(\mathrm{M}=81.68, \mathrm{SD}=6.48)$ groups (Table 1$)$. 
Comparison of Three Types of Stud Attachments on Retention and Strain Energy in the Mandibular Implant Supported Overdentures

\section{DISCUSSION}

The most common complaint of patients with lower full dentures is lack of stability and retention during function [35]. The best treatment options to overcome these complaints are implant-supported overdentures. To assess the quality of overdenture treatments, retention, stability and support should be considered simultaneously [38]. On the other hand, over the last three decades, implant supported overdentures have been becoming more popular. This could be due to increased patients' knowledge; or greater access of dentists to attachment systems [39].

Based on the results of the current study, by comparing the Ball, Positioner and Kerator attachments in implantium system, a significant difference was found in retention and strain energy. The greatest vertical load was observed in Ball attachment $(67.78 \mathrm{~N})$ and then Positioner attachment (47.25 N), and the least was observed in Kerator attachment (45.87 N).

In comparisons between groups of attachments, a significant difference was found between ball attachment and the other two groups; while the difference between Kerator and Positioner attachments was not statistically significant.

In oblique loading, the greatest retention was associated with Ball attachment $(88.07 \mathrm{~N})$ and after that Kerator (81.68 N), and the least retention was associated with Positioner attachment(39.19 N). These three groups showed significant differences in retention. While the difference between Positioner and the other two groups was statistically significant, no difference was found between Ball and Kerator attachments.

These findings are similar to that of previous studies [9, 40]. For strain energy, the Ball attachment used in this study was more successful than that of previous studies.

The absorbed strain energy during the placement of overdenture splits into two components, elastic component (reversible) and plastic component (nonreversible). In an ideal situation, contact surfaces should bear all the elastic strain; in the case of permanent deformation, the retention would be lost immediately[30]. Considering this, the strain energy for the attachments could be explained as the highest energy for both vertical and oblique loadings that is associated with Ball attachment (4.8 and $4.5 \mathrm{~J})$. The least energy strain in vertical loading is for Kerator attachment $(1.4 \mathrm{~J})$ and the least in oblique loading is for Positioner attachment (1.44 J).

In previous studies, the more recent attachments have not been evaluated for their retention quality and considering that the Kerator attachment has recently entered the market, this study was conducted to assess both retention and strain energy in these attachments.

After the placement of a denture, several forces in different directions will affect it. Retention is a force that resists against the movement of overdenture away from underlying tissues. In the evaluation of resistance against separation in implant-based overdentures, two issues should be considered: patient's viewpoint, which means the feeling of patients when they have dentures in their mouth and try to bring them out; and dentist's viewpoint, which is the Maximum Dislodging Force (MDF) that is measurable.

Utilization of Ball attachments by other companies such as Branemark has increased their retention and strain energy, which is in line with our results[2, 19]. Petropolous et al examined the retention and strain energy of stud attachments in implant-based overdentures and found the highest retention forces for both vertical and oblique directions in Zest Anchor Advanced Generation. They found the highest strain energy during vertical and oblique placements in Ball attachments[9].

Evaluation of the stud attachments' retention under masticatory forces simulation showed that masticatory forces mildly eroded the Ball attachment, and did not affect the retentive forces. However, for Locator attachment, the simulation forces made a change in nylon components of the attachment and subsequently reduced the retention of this system. Additionally, after 100000 cycles of masticatory force inductions, significant changes were examined in the retention of Locator's color codes, Blue inserts showed the highest decrease in retention (37\%) and no difference was observed in pink and white inserts [41].

Alsabecha et al (2010) reported that attachment systems with larger dimensions create a higher retentive force for lower uni-implant supported overdentures[42]. 
Comparison of Three Types of Stud Attachments on Retention and Strain Energy in the Mandibular Implant Supported Overdentures

In another study, Branchi et al (2009) found that matrices with gold and Teflon alloys had the highest retention in a three-year function simulation. In their study, titanium and O-ring matrices had a continuous decrease in retention and Ball attachment in combination with titanium matrix showed the highest extent of erosion [24].

In their study, Uldag et al (2012) examined the retention of different attachment systems in overdentures supported by two or three implants in the mandible. The retention was found to be higher for three attachments (Locator) compared to two attachments [43]. In this study, all the patterns showed a decrease in retention from the primary test to the last loadings. Use of the Locator attachments in implant supported overdentures compared to Bar/ Clip attachments induces a lower strain to implants in the mandible [44].

The results of higher retention for Ball attachments could be related to their new design, Universal Hinge Movement, which allows higher rotation compared to previous designs [45]. These attachments have an extra-radicular design and the key part (patrix) is on outer surface of implant abutment. In standard Ball attachment a plastic cap (matrix) is used and the retention is provided by a flexible plastic O-ring with capability of moving above the height of contour (HOC) attachment. It has been indicated that attachments with larger dimensions provide larger cross sections and subsequently higher retentions [46].

Recentclinicalstudieshaveproven thelowerresorption rates of marginal bone with Ball locator attachments compared to Implant Locator attachments. This could be due to the higher splitting effect in implants compared to Locator attachments.

All the studies in this field including the current study have limitations, and the most important one is their experimental nature. There is no doubt that result of these studies in clinical situation considering the different condition of the mouth including saliva, $\mathrm{pH}$, and temperature might be different. Additionally, considering the limitations in budget and facilities, increasing the number of samples and repeating the cycles was not feasible.

\section{REFERENCES}

[1] Sivaramakrishnan, G. and K. Sridharan, Comparison of implant supported mandibular overdentures and conventional dentures on quality of life: a systematic review and meta-analysis of randomized controlled studies. Aust Dent J, 2016. 61(4): p. 482-488.

[2] Critchlow, S.B. and J.S. Ellis, Prognostic indicators for conventional complete denture therapy: a review of the literature. J Dent, 2010. 38(1): p. 2-9.

[3] DaFontoura Frasca, L.C., etal., Evaluation of retention forces and resistance to fatigue of attachment systems for overdentures: plastic and metal components. Implant Dent, 2014. 23(4): p. 451-5.

[4] Thomason, J.M., et al., Mandibular two implantsupported overdentures as the first choice standard of care for edentulous patients--the York Consensus Statement. Br Dent J, 2009. 207(4): p. 185-6.

[5] Muller, F., et al., Knowledge and attitude of elderly persons towards dental implants. Gerodontology, 2012. 29(2): p. e914-23.

[6] Awad, M.A., et al., The effect of mandibular 2-implant overdentures on oral health-related quality of life: an international multicentre study. Clinical Oral Implants Research, 2014. 25(1): p. 46-51.

[7] Hasan, I., et al., Changes in biting forces with implant-supported overdenture in the lower jaw: A comparison between conventional and mini implants in a pilot study. Annals of Anatomy Anatomischer Anzeiger, 2016. 208: p. 116-122.

[8] Adell, R., et al., A 15-year study of osseointegrated implants in the treatment of the edentulous jaw. International Journal of Oral Surgery, 1981. 10(6): p. 387-416.

[9] Petropoulos, V.C. and F.K. Mante, Comparison of retention and strain energies of stud attachments for implant overdentures. J Prosthodont, 2011. 20(4): p. 286-93.

[10] Mensor,M.C.,Jr,,Attachmentfixationforoverdentures. Part I. J Prosthet Dent, 1977. 37(4): p. 366-73.

[11] Daou, E.E., Stud attachments for the mandibular implant-retained overdentures: Prosthetic complications. A literature review. The Saudi Dental Journal, 2013. 25(2): p. 53-60.

[12] Gozneli, R., et al., Retention behaviors of different attachment systems: precious versus nonprecious, precision versus semi-precision. Dent Mater J, 2013. 32(5): p. 801-7. 
Comparison of Three Types of Stud Attachments on Retention and Strain Energy in the Mandibular Implant Supported Overdentures

[13] Seo, Y.H., et al., Clinical evaluation of mandibular implant overdentures via Locator implant attachment and Locator bar attachment. J Adv Prosthodont, 2016. 8(4): p. 313-20.

[14] Trakas, T., et al., Attachment systems for implant retained overdentures: a literature review. Implant Dent, 2006. 15(1): p. 24-34.

[15] Leem, H.-W., et al., A study on the changes in attractive force of magnetic attachments for overdenture. J Adv Prosthodont, 2016. 8(1): p. 9-15.

[16] Boeckler, A.F., et al., Corrosion of dental magnetattachments for removable prostheses on teeth and implants. J Prosthodont, 2009. 18(4): p. 301-8.

[17] Takada, Y., N. Takahashi, and O. Okuno, Corrosion characteristics of magnetic assemblies composing dental magnetic attachments, in Interface Oral Health Science 2007: Proceedings of the 2nd International Symposium for Interface Oral Health Science, Held in Sendai, Japan, Between 18 and 19 February, 2007, M. Watanabe, et al., Editors. 2007, Springer Japan: Tokyo. p. 343-344.

[18] Scherer, M.D., et al., Comparison of retention and stability of two implant-retained overdentures based on implant location. J Prosthet Dent, 2014. 112(3): p. 515-21.

[19] Bergendal, T. and B. Engquist, Implant-supported overdentures: a longitudinal prospective study. Int J Oral Maxillofac Implants, 1998. 13(2): p. 253-62.

[20] Abi Nader, S., et al., Effect of simulated masticatory loading on the retention of stud attachments for implant overdentures. J Oral Rehabil, 2011.38(3): p. 157-64.

[21] Cehreli, M.C., et al., Systematic review of prosthetic maintenance requirements for implant-supported overdentures. Int J Oral Maxillofac Implants, 2010. 25(1): p. 163-80.

[22] Karabuda, C., M. Yaltirik, and M. Bayraktar, $A$ clinical comparison of prosthetic complications of implant-supported overdentures with different attachment systems. Implant Dent, 2008. 17(1): p. 74-81.

[23] Anas El-Wegoud, M., et al., Bar versus ball attachments for implant-supported overdentures in complete edentulism: A systematic review. Clin Implant Dent Relat Res, 2018. 20(2): p. 243-250.
[24] Branchi, R., et al., Resistance to wear of four matrices with ball attachments for implant overdentures: a fatigue study. J Prosthodont, 2010. 19(8): p. 614-9.

[25] Sadowsky, S.J., Treatment considerations for maxillary implant overdentures: a systematic review. J Prosthet Dent, 2007. 97(6): p. 340-8.

[26] Stoker, G.T., D. Wismeijer, and M.A. van Waas, $A n$ eight-year follow-up to a randomized clinical trial of aftercare and cost-analysis with three types of mandibular implant-retained overdentures. J Dent Res, 2007. 86(3): p. 276-80.

[27] Petropoulos, V.C. and W. Smith, Maximum dislodging forces of implant overdenture stud attachments. Int J Oral Maxillofac Implants, 2002. 17(4): p. 526-35.

[28] Chung, K.-H., et al., Retention Characteristics of Attachment Systems for Implant Overdentures. Journal of Prosthodontics, 2004. 13(4): p. 221-226.

[29] Rutkunas, V., H. Mizutani, and H. Takahashi, Evaluation of stable retentive properties of overdenture attachments. Stomatologija, 2005. 7(4): p. 115-20.

[30] Evtimovska, E., et al., The change in retentive values of locator attachments and hader clips over time. J Prosthodont, 2009. 18(6): p. 479-83.

[31] Burns, D.R., et al., Prospective clinical evaluation of mandibular implant overdentures: Part I-Retention, stability, and tissue response. J Prosthet Dent, 1995. 73(4): p. 354-63.

[32] Kutkut, A., et al., A systematic review of studies comparing conventional complete denture and implant retained overdenture. J Prosthodont Res, 2018. 62(1): p. 1-9.

[33] Goodacre, C.J., et al., Clinical complications with implants and implant prostheses. J Prosthet Dent, 2003. 90(2): p. 121-32.

[34] Stephens, G.J., et al., The influence of interimplant divergence on the retention characteristics of locator attachments, a laboratory study. J Prosthodont, 2014. 23(6): p. 467-75.

[35] Kim, S.-M., et al., Comparison of changes in retentive force of three stud attachments for implant overdentures. J Adv Prosthodont, 2015. 7(4): p. 303-311. 
Comparison of Three Types of Stud Attachments on Retention and Strain Energy in the Mandibular Implant Supported Overdentures

[36] Cune, M., et al., Patient satisfaction and preference with magnet, bar-clip, and ball-socket retained mandibular implant overdentures: a cross-over clinical trial. Int J Prosthodont, 2005. 18(2): p. 99-105.

[37] Petropoulos, V.C., W. Smith, and E. Kousvelari, Comparison of retention and release periods for implant overdenture attachments. Int J Oral Maxillofac Implants, 1997. 12(2): p. 176-85.

[38] Feine, J.S., et al., The McGill consensus statement on overdentures. Mandibular two-implant overdentures as first choice standard of care for edentulous patients. Gerodontology, 2002. 19(1): p. 3-4.

[39] Renner, R.P., The overdenture concept. Dent Clin North Am, 1990. 34(4): p. 593-606.

[40] Sultana, N., D.W. Bartlett, and M. Suleiman, Retention of implant-supported overdentures at different implant angulations: comparing Locator and ball attachments. Clin Oral Implants Res, 2017.

[41] Tehini, G., et al., Effect of Simulated Mastication on the Retention of Locator Attachments for ImplantSupported Overdentures: An In Vitro Pilot Study. J Prosthodont, 2017.
[42] Alsabeeha, N., et al., Attachment systems for mandibular single-implant overdentures: an in vitro retention force investigation on different designs. Int J Prosthodont, 2010. 23(2): p. 160-6.

[43] Uludag, B. and S. Polat, Retention characteristics of different attachment systems of mandibular overdentures retained by two or three implants. Int J Oral Maxillofac Implants, 2012. 27(6): p. 1509-13.

[44] Yoo, J.S., et al., Stress analysis of mandibular implant overdenture with locator and bar/clip attachment: Comparative study with differences in the denture base length. J Adv Prosthodont, 2017. 9(3): p. 143-151.

[45] Doukas, D., et al., The influence of interimplant distance and attachment type on the retention characteristics of mandibular overdentures on 2 implants: 6-month fatigue retention values. Int J Prosthodont, 2008. 21(2): p. 152-4.

[46] Chung, K.H., et al., Retentive characteristics of overdenture attachments during repeated dislodging and cyclic loading. Int J Prosthodont, 2011. 24(2): p. 127-9.

Citation: Gholamreza Esfahanizadeh, Parvaneh Lavasani Navai. Comparison of Three Types of Stud Attachments on Retention and Strain Energy in the Mandibular Implant Supported Overdentures. Archives of Dentistry and Oral Health. 2020; 3(1): 14-20.

Copyright: (C) 2020 Gholamreza Esfahanizadeh, Parvaneh Lavasani Navai. This is an open access article distributed under the Creative Commons Attribution License, which permits unrestricted use, distribution, and reproduction in any medium, provided the original work is properly cited. 